\title{
Community-based adaptation to climate change: lessons from Tanna Island, Vanuatu
}

\author{
Tahlia Clarke \\ School of Earth and Environmental Sciences, University of Queensland, Brisbane, Australia \\ tahlia.clarke@uq.net.au
}

Karen E. McNamara

School of Earth and Environmental Sciences, University of Queensland, Brisbane, Australia karen.mcnamara@uq.edu.au (corresponding author)

\section{Rachel Clissold}

School of Earth and Environmental Sciences, University of Queensland, Brisbane, Australia rachel.clissold@uq.net.au

\section{Patrick D. Nunn}

School of Social Sciences, University of the Sunshine Coast, Sippy Downs, Australia pnunn@usc.edu.au

\begin{abstract}
Community-based adaptation has gained significant international attention as a way for communities to respond to the increasing threats and complex pressures posed by climate change. This bottom-up strategy represents an alternative to the prolonged reliance on, and widespread ineffectiveness of, mitigation methods to halt climate change, in addition to the exacerbation of vulnerability resulting from top-down adaptation approaches. Yet despite the promises of this alternative approach, the efficacy of community-based adaptation remains unknown. Its potential to reduce vulnerability within communities remains a significant gap in knowledge, largely due to limited participatory evaluations with those directly affected by these initiatives, to determine the success and failure of project design, implementation, outcomes and long-term impact. This paper seeks to close this gap by undertaking an in-depth evaluation of multiple community-based adaptation projects in Tanna Island, Vanuatu and exploring community attitudes and behavioural changes. This study found that future community-based adaptation should integrate contextual specificities and gender equality frameworks into community-based adaptation design and implementation, as well as recognise and complement characteristics of local resilience and innovation. In doing this, the critical importance of looking beyond assumptions of Small Island Developing States (SIDS) as homogenous, primarily vulnerable to climate change and lacking resilience, was also recognised.
\end{abstract}

Keywords: adaptation, climate change, community-based resilience, Small Island Developing States (SIDS), vulnerability

https://doi.org/10.24043/isj.80

(C) 2019-Institute of Island Studies, University of Prince Edward Island, Canada. 


\section{Introduction and literature}

Climate change is one of the most complex challenges facing the world today. The irreversible nature of climate change threatens to significantly impact human and biological systems, undermining not only future ecosystem sustainability but also the livelihoods, security and wellbeing of current and future generations. Climate change threatens to deepen vulnerabilities, reverse hard-won socio-economic gains, and challenge prospects for sustainable development across the globe.

In light of the cumulative negative impacts of climate change, adaptation has become an inevitable and urgent priority (Betzold, 2015). It is becoming increasingly recognised, however, that top-down, centralised adaptation approaches are plagued with inefficiencies such as failures to adequately address the needs of vulnerable populations and their inability to acknowledge the complexity/dynamics of local contexts (Ayers \& Forsyth, 2009; Hedger et al., 2008). As a result, non-governmental organisations (NGOs) and donors are increasingly diverting efforts towards bottom-up approaches like community-based adaptation (CBA) (Betzold, 2015) that are believed to improve responses to climate change (Ayers \& Forsyth, 2009; Reid \& Schipper, 2014). CBA is a holistic, multi-dimensional, transdisciplinary and place-based approach that focuses on the interrelations between socio-economic, cultural, political and environmental stressors to which communities are exposed. CBA empowers communities to take action on climate change and build resilience, whilst also acknowledging the necessity of tailoring interventions (as in, initiatives or projects) to local contexts (Ayers \& Forsyth, 2009; Kirkby et al., 2017; Reid, 2015). Although this approach is relatively new, it is considered fundamental to effective sustainable adaptation as it facilitates the direct involvement of the community in design and implementation, as well as the acknowledgement of local priorities, needs, knowledge and capacity (Ayers \& Forsyth, 2009; Reid, 2015).

Despite the theoretical advantages of CBA as outlined above, there is little evidence of its impact in decreasing vulnerability and increasing resilience to climate change (Buggy \& McNamara, 2016). One reason is that there are few replicable approaches available due to a focus on the theory behind adaptation rather than the elements of successful practical implementation (Ensor et al., 2018; Nunn et al., 2014; Reid \& Schipper, 2014). Consequently, there is a need for in-depth evaluations of CBA initiatives to understand elements of success and failure, and through this, to optimise future CBA efforts (Wheeler \& Von Braun, 2013). In this context, identifying and sharing successful elements of CBA is crucial to its effective use by NGOs, donors and governments, and for achieving long-term resilience in the Pacific Islands and other Small Island Developing States (SIDS) (Kirkby et al., 2017; Nunn \& Kumar, 2018). In response to this gap, this paper will aim to evaluate CBA initiatives within two communities on Tanna Island, Vanuatu and, through this, determine the efficacy of CBA in building resilience and tackling vulnerabilities, while also identifying the fundamental elements of success that may be applied to future initiatives.

Despite contributing little to global greenhouse gas emissions, SIDS such as Vanuatu have often been characterised by a narrative which depicts them as inherently vulnerable to the adverse impacts of climate change (Moore, 2010; Nunn \& Kumar, 2018; Nurse et al., 2014). This disproportionate burden is largely attributable to the comparative remoteness and small size of most islands, their disproportionately high exposure to hazards, a range of 
economic and political factors, several social and cultural characteristics, as well as a high dependency on natural resources and ecosystem services (Betzold, 2015). Climate change has already resulted in significant and disruptive changes across sectors crucial to the livelihoods and economic activities of many island populations. Yet regardless of the increased flow of adaptation funding into the region over the past few decades, island populations remain perceived as highly exposed to the current and projected impacts of climate change (Kirkby et al., 2017; McNamara, 2013).

Although this narrative of SIDS has supported a proliferation of funding and climate change awareness in the region, it also entails several negative consequences. This includes, for example, an imagery that posits islands as non-resilient places that must rely on external assistance, which makes the narrative undisputable for policy (Malatesta \& Schmidt di Friedberg, 2017), as well as the privileging of climate change which can distract from and depoliticise other prominent development challenges (Kelman, 2014). Further, this narrative has supported the generalisation of SIDS as a category devoid of differences in the global climate change arena (Malatesta \& Schmidt di Friedberg, 2017). Critical reflections and rereadings of these existing narratives for SIDS (see e.g. Kelman, 2018) are, therefore, necessary. Through exploring the effectiveness and lessons learnt from CBA in Vanuatu, this study will attempt to nuance and balance these assumptions and look beyond SIDS as a homogenous group, recognising other prominent development challenges and their existing resilience.

\section{Resilience, vulnerability and adaptation}

As the three core concepts in this study, this section will briefly introduce the links between resilience, vulnerability and adaptation. Adaptation involves adjustments to natural and/or human systems in response to expected impacts of climate change (Ayers \& Forsyth, 2009; Smit \& Wandel, 2006). A community's vulnerability and resilience, and the complex relationship between them, shed light on the system's ability to respond, cope and adapt to climate change. Both vulnerability and resilience are geographically, socially and culturally context specific, and in a continuous state of flux (Adger, 2006). It is essential to understand and address the multidimensional nature of these concepts across geo-physical, socio-cultural, political and economic contexts to ensure successful and sustainable adaptation (Cardona et al., 2012; Folke, 2006; Kais \& Islam, 2016).

Central to understanding and reducing vulnerability is addressing and strengthening societal resilience to cope with shocks and uncertainty (Bene et al., 2014; Cardona et al., 2012). Building resilience is key to adapting to climate change as it centralises the strength and unique characteristics of individuals and groups, and pursues approaches that maintain essential functions, identities and structures, all of which enable communities to act as agents in their own adaptation (Cardona et al., 2012; Dixon \& Stringer, 2015; Folke et al., 2010). Focusing on building resilience has thereby become increasingly recognised as a target strategy within disaster risk reduction and climate change adaptation (Cardona et al., 2012; Dixon \& Stringer, 2015). In recognising the role that both resilience and vulnerability play in adaptation, this study will refer to both concepts in evaluating CBA.

\section{Community-based adaptation}

CBA design and implementation aims to recognise local contexts, priorities and needs to ensure appropriate and effective initiatives or projects, while also attaining community support 
and empowering individuals to make changes themselves (McNamara, 2013; Reid et al., 2009). The literature to date has noted the importance of local context for optimising outcomes in CBA initiatives. There is no 'one size fits all' approach (Nunn \& Kumar, 2018). CBA must be context dependent and flexible in light of inevitable changes, acknowledging ways in which communities might be evolving (Barnett \& Waters, 2016; Ensor et al., 2018; Reidy, 2012). Core to integrating contextual specificities in CBA design and implementation is community involvement and participation, and more specifically, the incorporation of traditional knowledge within all phases of CBA (Buggy \& McNamara, 2016; Reid et al., 2009). As argued by Reid et al. (2016, p. 22), "much knowledge and capacity on how to adapt is embedded in societies and cultures." Community involvement invariably results in heightened understanding of local context, appropriateness of design, greater project uptake, more effective allocation of resources, and greater overall support for initiatives (Bahadur et al., 2010; Gwali, 2014). CBA recognises that people are agents in their own adaptation. Acquiring the knowledge and skills to begin adapting, assessing and monitoring enables participants to accept uncertainty and respond proactively to change, thereby creating opportunities for self-organisation, community driven innovation and transformation (Interagency Resilience Working Group, 2012; Kais \& Islam, 2016).

CBA focuses on building the resilience of all, and thus the pre-existing marginalisation within communities must be addressed within design and implementation. Equity, as a part of CBA approaches, is critical to overall sustainability and community wellbeing. The impacts of climate change are not felt equally. The term 'community' implies a cohesive and homogenous network, yet in reality communities are diverse and multi-faceted in their individual priorities, needs, vulnerabilities and capacities as well as affected by social dynamics, traditional norms and opportunities (Buggy \& McNamara, 2016; Kais \& Islam, 2016; Kirkby et al., 2017). The existing complexities are differentiated along lines of gender, age, socioeconomic class and religion (Bryan \& Behram, 2013; Kais \& Islam, 2016).

Critical to vulnerability is the variable of gender, with climate change being consistently linked to the exacerbation of gender inequalities (Bendlin, 2014; Bryan \& Behram, 2013; UNDP, 2010). Socially and culturally constructed roles and responsibilities, structural barriers and power dynamics within communities result in the heightened vulnerability of women and girls to climate change (Bendlin, 2014; Richmond \& Sovacool, 2012). Gendered cultural barriers influence women's and girls' individual sensitivity and their ability to adapt to disturbances, shocks and stresses (Webb et al., 2017). Not only are women and girls more vulnerable, but they also have different needs and priorities when responding to variability and change (Bryan et al., 2015). Without addressing such underlying causes of vulnerability, CBA has the potential to reinforce and exacerbate inequalities (Cardona et al., 2012).

With adaptation interventions often relying on longer-term behaviour changes and an effective approach to complex drivers of vulnerability, the success of CBA interventions depends on flexibility of design, resources and timeframes (Bryan et al., 2015). Participatory processes and transformative community change requires "time to develop flexible funding [...] They do not fit with pre-determined calendars, budgets and outputs" (Reid \& Schipper, 2014, p. 8). There is, therefore, a critical need for NGOs, donors and governments to recognise the time needed for dynamic and transformative adaptation (Bryan et al., 2015; Demetriades, 2007). In addition, the fluidity of social, economic, political and environmental 
contexts demands flexibility of initiative/project design to adapt to challenges and changes as they arise (Bahadur et al., 2010; Cardona et al., 2012; Reidy, 2012).

Yet despite the growing theoretical basis of CBA, and the consistency of critical elements across literature, more concrete evidence on the successes and failures of practical implementation of CBA is needed to demonstrate its efficacy towards building individual and community resilience. As put by Kirby et al. (2017, p. 10) in their recent attempt to clarify the elements of CBA, "evidence of success is needed to stimulate the mainstreaming of CBA into existing adaptation and development policies and programmes [...] to identify and share important lessons that can inform the work of other actors."

\section{Case study: Whitesands region, Tanna Island, Vanuatu}

Vanuatu, an archipelagic state in the South-West Pacific, represents a significant example of how people and societies cope with and respond to environmental change. In the latest World Risk Report, Vanuatu was classified as the country most at risk to natural hazards (Heintz et al., 2018): $81 \%$ of Vanuatu's landmass and 76\% of its inhabitants are uncommonly vulnerable to hazards such as volcanic eruptions, cyclones, earthquakes, droughts, tsunamis, flooding and landslides (Richmond \& Sovacool, 2012). For Vanuatu, there is high confidence in a future increase in mean and extremely high temperatures, intensity of extreme rainfall events, sealevel rise, and ocean acidification (BOM \& CSIRO, 2014). Like many other Pacific countries, the people of Vanuatu are increasingly exposed to livelihood impacts associated with climate change and other challenges (Heintz et al., 2018).

The country has a comparatively low Human Development Index (0.616), ranked 131 out of 187 countries, based on social and economic characteristics (United Nations, 2015). As a low-to-middle-income country, Vanuatu is heavily dependent on foreign aid (Schmaljohann \& Prizzon, 2014). A large share of the country's budget is financed through bilateral and multilateral sources, with official development assistance representing approximately $13 \%$ of Gross National Income in 2012 and contributing 20-30\% of the Government's budget in the 2000s (Schmaljohann \& Prizzon, 2014).

To further localise this study, two communities in the Whitesands region on Tanna Island, southern province of Tafea, were studied (see Figure 1). Tanna is a volcanic island containing $80 \%$ of the population in Tafea Province, which is identified as the most disasterprone in Vanuatu (NACCC, 2007). This province was also devastated by category 5 Cyclone Pam in March 2015. The case study communities, Waisisi and Imaio, were selected because of their comparatively high dependence on natural resources and significant exposure to hazards, shocks and stressors.

Community members in both Waisisi and Imaio depend on subsistence agriculture. With often inadequate food supply and potable water, these communities appear particularly vulnerable to future impacts of climate change. Both communities are witnessing alterations to their natural environment, including sea-level rise, extreme rainfall and flooding, declining crop yields and quality, drought, water shortages, declining environmental health, more intense cyclone activity, and volcanic ash fall (preliminary findings of the 2016 Census, provided by CARE representatives 2017). 


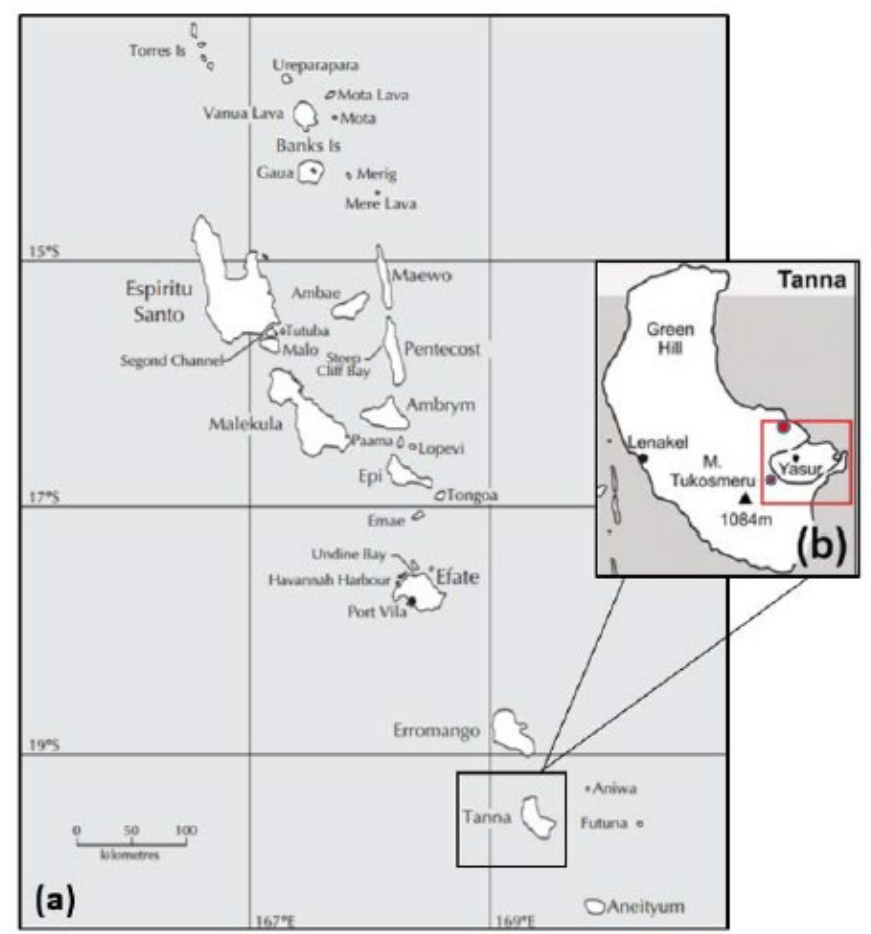

Figure 1: Map of Vanuatu (a) (Dinnen et al., 2010) and Tanna Island (b) (Métrich et al., 2011). The region of Whitesands (outlined in red) represents the case study site including the communities of Waisisi (top red marker) and Imaio (bottom red marker).

\section{Overview of the 'Yumi redi long klamet jenis' project}

This study focuses on the adaptation initiatives implemented by CARE International, in partnership with Save the Children, throughout 2016 and 2017. Funded by the Pacific American Climate Fund, the project sought to address the challenges presented by climate change via locally developed plans and strategies, to increase the resilience of communities (especially women, youths, boys, and girls) to shocks, stresses and future uncertainty. The communities that formed part of the project were involved in both implementation and monitoring stages: a model CBA approach. The design phase of the project was completed via the use of secondary community data such as endline project results, evaluations, staff consultations and direct feedback from the community in regards to past projects. Table 1 provides an overview of the project's objectives.

As detailed in the following methods section, this study focuses on the CBA project components of climate change adaptation and disaster risk reduction training, water resource management, and food/agricultural management and training. Overall the project aims to increase resilience through awareness, cooperation and empowerment, and the strengthening of food and water security in times of climatic stress. 
Table 1: Objectives of the 'Yumi redi long klamet jenis' project. Source: CARE Vanuatu \& Save the Children, 2017.

\begin{tabular}{|c|c|c|}
\hline Objective & Description & Activities \\
\hline $\begin{array}{l}\text { Climate change } \\
\text { adaptation (CCA) } \\
\text { and disaster risk } \\
\text { reduction (DRR) } \\
\text { awareness and } \\
\text { training }\end{array}$ & $\begin{array}{l}\text { Increasing of awareness and } \\
\text { capacity to anticipate, plan for and } \\
\text { respond to the impacts of climate } \\
\text { change }\end{array}$ & $\begin{array}{l}\text { Promoting gender balance in all } \\
\text { community committees, Climate } \\
\text { Change Adaptation and Disaster Risk } \\
\text { Reduction awareness, development of } \\
\text { community action plans and gender } \\
\text { training and women's empowerment }\end{array}$ \\
\hline $\begin{array}{l}\text { On the ground } \\
\text { climate change } \\
\text { adaptation }\end{array}$ & $\begin{array}{l}\text { Implement context-appropriate } \\
\text { community-based climate change } \\
\text { adaptation }\end{array}$ & $\begin{array}{l}\text { Agriculture and food security activities } \\
\text { surrounding training in climate resilient } \\
\text { practices, establishment of demonstration } \\
\text { plots, food and nutrition training and } \\
\text { solar food preservation; and water } \\
\text { resource management }\end{array}$ \\
\hline
\end{tabular}

\section{Methods}

The method for this research was designed as part of a larger research study across four Pacific countries. It was designed with a number of partner organisations, including CARE, to ensure useful lessons could inform their own work in the future. The method uses both focus groups and interviews. Evaluation indicators were also developed to ensure a holistic qualitative assessment of the CBA initiatives/projects. These indicators were established via an ad hoc review of literature from the monitoring and evaluation field and monitoring and evaluation frameworks specially for climate change adaptation (for example, Bours et al., 2013; Hedger et al. 2008; Villanueva 2011). By comparing existing CBA frameworks, five key indicators for this study were developed to assess the outcomes of the initiatives: appropriateness, effectiveness, equity, impact and sustainability.

\section{Qualitative data collection}

A focus group guide was developed with open-ended questions tailored to assess the extent of success or failure of CBA initiatives. The guide also included questions relating to sociodemographics, community vulnerabilities and livelihood assets. Developed by a team of Australian-based researchers in consultation with various partner organisations, this guide has been utilised across four countries in the Pacific region: Federated States of Micronesia, Fiji, Kiribati and Vanuatu. The guides were altered to local context through the aid of partner organisations within the region, to ensure effective participant understanding across the islands.

Within the two communities of Waisisi and Imaio, four focus group discussions were conducted to evaluate the implemented CBA project. CARE representatives recruited voluntary research participants who had been involved with the project. In total, 31 participants (13 males and 18 females) were involved in this study across the two communities. Participants included individuals in young adulthood (18-40 years old), middle adulthood (41-65 years old) and the elderly (65+ years old). Most participants had attained a primary 
level of schooling, although many elderly participants had received no formal education. A number of the participants were members of community committees established by CARE, and were involved in the implementation and continuation of the adaptation project.

Focus groups were conducted for approximately two to three hours in accessible common spaces (a church in Imaio and a community fish house in Waisisi). Participants were separated by gender in order to facilitate the exploration of varying views and experiences and to encourage participation in a comfortable setting, which was a necessity in light of the culturally embedded power relations and male dominance in these communities (Bendin, 2014; Bene et al., 2014). The research was undertaken with the aid of two CARE local Vanuatu representatives who facilitated the focus groups in the national language of Bislama and translated into the local language as required.

At the outset of discussions, participants were asked to select the two most pertinent adaptation components arising from the CARE project. The community of Waisisi selected (1) climate change awareness (CCA) and disaster risk reduction (DRR) training and (2) water resource management, whereas the Imaio community participants preferred to focus on (1) water resource management and (2) food/agricultural management. These adaptation activities were then discussed via the facilitation of open-ended questions under each of the evaluation indicators.

Following the focus groups, six semi-structured interviews (three men and three women) were undertaken with key members from the focus groups. Interview questions were based on the most prevalent themes arising from the focus groups. Both the individual interviews and the focus group discussions formed the basis for data analysis. This basis provides insights into the elements of project design and implementation, enabling the analysis to delve into the potential successes and failures of CBA.

The authors of this study recognise a number of limitations in data collection. First, a larger sample size would have increased the impact and influence of the results collated. Second, through the support provided by CARE in the facilitation of this research, there is a high likelihood that the participants had a positive response bias. Furthermore, due to the short period of implementation prior to the commencement of this study, further evaluation of the CBA project should be conducted at a later date to determine the long-term impacts.

\section{Data analysis and synthesis}

Utilising the NVivo software to examine and organise the large dataset, the data was reviewed using content analysis. The semi-structured interview data was disseminated across the appropriate corresponding indicator categories, aiding comparison with the focus group data.

The data was coded into categories under each evaluation indicator, via the assessment of keywords, main themes and patterns, the interpretation of underlying context and the comparison of datasets. The data, therefore, does not quantify participants' responses or views but, instead, indicates the key qualitative themes that emerge under each evaluation indicator. The data was analysed separately for each community, and also by gender, to establish the key successes and failures of the project through multiple perspectives. The analyses were then combined and re-coded to deduce a more detailed analysis of the project as a whole. 


\section{Results}

Through analysis of the primary data collected, community attitudes and behavioural changes demonstrate that CBA has aspects of both success and failure that influence the ability of projects/initiatives to reduce vulnerability and increase resilience. The results are discussed below and are guided by the evaluation indicators.

\section{Appropriateness}

All participants in this study concluded that the primary activities implemented by CARE suited the communities' priorities and needs, and were appropriate to the challenges faced by the communities. The main threats to livelihoods and wellbeing were attributed to the occurrence of hazards, and access and availability to water and food resources arising from changes in temperature and rainfall.

Food management activities, including the demonstration plot and preservation techniques, met the needs of improved food security as prioritised by Imaio community members. With changes to temperature, rainfall and hazard occurrence over the past few decades, participants noted the impacts of climate change on crop yields and planting seasons as significantly impacting overall agricultural output and threatening food security. With regards to water management, the activities addressed a primary challenge for both Waisisi and Imaio communities, which was the lack of access to sustainable supply and sources of water. In times of climatic stress and variability, particularly in the current period of long-term drought, the communities face difficulties securing water.

The CCA/DRR training was portrayed as essential to increasing participant knowledge on the occurrence and impacts of climate change and the associated hazards. Participants reiterated the necessity of incorporating modern/scientific climate projections into traditional livelihoods owing to the lessening effectiveness of local traditional signs and knowledge:

We used to follow traditional signs [...] but all of the sudden the weather would change and we weren't sure what to expect. (Female participant, Waisisi)

For these reasons, the training activities as part of this CBA project were deemed by the communities to be appropriate to their needs.

There was however a major concern noted by participants, which related to the materials and design elements. The use of non-traditional materials in implementation attracted negative views from both communities. All participants noted the inability to replace plastic elements because of the price of the materials, prohibitive in such cash-marginalised economies. The participants recommended the use of traditional, local and affordable materials, such as bamboo, to be utilised for any further projects:

The training is good but the problem is we can't afford to get all of these things [...] It would be better if you [CARE] could take something that is already inside of the community and use that. (Male participant, Waisisi)

Factoring in this concern about the appropriateness of materials has been an oversight of the project and has impacted its success. 


\section{Effectiveness}

Based on the group discussions, the participants believed they developed new knowledge, skills and understanding of climate change, hazards and disasters. These activities have increased community motivation to take action to safeguard livelihoods, encouraging the prioritisation of adaptation within their communities.

Prior to CARE's CCA and DRR awareness training, the participants noted limited response and preparation towards climate change and the associated warnings because of a lack of community knowledge about its nature. The project aided in defining and understanding specific roles and responsibilities of individuals and households, increasing the ability of and overall cooperation in these communities to respond and adapt to the impacts of climate change and disasters:

Now the men, women and children know what to do when they hear a warning. Before CARE's training we had no idea what to do. (Female participant, Waisisi)

At first I never knew of the term climate change, even though there have been many changes in the community, we didn't take it very seriously. After CARE implemented climate change activities, we came to the workshops and heard about awareness for the very first time and realised that the changes we were seeing was the term climate change. (Female interview participant, Waisisi)

Prior to the water management training, participants noted a lack of prioritisation of water management as a way of adapting to climate change. The training increased the value placed on water management, with a heightened awareness of its criticality in times where access, quantity and quality were limited. Community attitudes and behavioural changes displayed project effectiveness in encouraging water saving techniques, the use of recycled water, and overall improved sanitation and hygiene. Both communities noted that they continue to implement the knowledge gained in this training due to the positive outcomes they have witnessed:

When we saw that the water was dirty we just threw it away instead of using it, after the training we realised that we can use the water to do something else [...] After washing the dishes and crops for food preparation we use the dirty water to water the flowers and feed the animals. (Male participant, Waisisi)

We have to walk long distances to get water but with the knowledge we have now it helps us to save water [...] We can manage it when water is hard to find. (Female participant, Waisisi)

After the training we came to realise [...] what happens if we run out? We realised that after we take water home, we have to save it somewhere instead of wasting it or throwing it out. (Female participant, Imaio) 
Within Imaio, the demonstration plot and solar preservation techniques increased community recognition of the need to adapt farming techniques to increase yield success and food security. The initial implementation of new cropping techniques, pest control methods, and the provision of an agriculture handbook were successfully incorporated in community livelihoods. The solar preservation activity was also strongly endorsed by the community. The project was effective in initial implementation as it included practical training methods and enabled the community to store food for everyday use, and in times of disasters, enabling the community to improve its food security. Participants noted traditional knowledge about food preservation was less effective than the modern form of solar preservation implemented by CARE:

Before we found that our crops were not growing and now we have new ways to try instead of keep trying the old methods. (Male participant, Imaio)

Because we live in the disaster zone close to the volcano, we need the solar dryer so we can preserve food to get us prepared for a disaster. When a disaster comes, sometimes it can destroy all the crops, but with the food preserved from drying [...] each household can survive. (Female participant, Imaio)

Community committees, referred to as the Community Disaster and Climate Change Committee (CDCCC) in these communities, were created at the CCA and DRR trainings/workshops and represented an important resource for sustaining project effectiveness. They were shown to be crucial in strengthening overall community resilience as they were viewed as spearheading preparation and preparedness while also acting as a nexus for further community involvement and improved community cooperation. Through information dispersal and aiding individuals to understand their roles and responsibilities in times of need, participants noted that the members of the CDCCC played a crucial role in ensuring disaster preparedness and the ability to adapt to climate change and the increasing associated risks:

We have a role to play to show the community we can work together and when they see this it motivates them. (Male participant, CDCCC member, Waisisi)

Despite the important role of these committees, it was found that a limiting factor to effectiveness was the lack of consultation between this committee and the rest of the community on occasion. In these situations, the information provided by CARE to the committee was not communicated. It is therefore essential to ensure that committees carry out their roles and responsibilities effectively.

A final concern raised by communities was the environmental context, which was believed to have influenced project effectiveness. In the case studies examined, the geographical proximity of the active volcano of Mt Yasur and the periodic ash falls resulted in impacts on agricultural output and water sources, and also damaged materials used during the project. Despite the appropriateness of the activities and overall project to community needs and priorities, the lack of consideration for, and knowledge of, the potential impacts of geographical context presented a significant limitation to the project's ongoing success: 
Everything seemed like it went well but the only problem is our friend (the volcano) $[\ldots]$ It is the reason why parts of the projects didn't go well. (Female participant, Imaio)

CARE established 17 demonstration plots across two provinces of Vanuatu, and they reported that the majority of demonstration plots were successful, to varying degrees, though there were problems with ash fall hindering the growth of some plots in Tanna. The variance in context between communities of the same island, highlights the difficulties of scaling out project design, and the critical need to acknowledge variations in context, for CBA project success. CBA design must fully consider the impacts, or potential impacts, of the local context, and when the impacts are uncertain (i.e. impacts of ash of crop growth), the need for flexibility of design to combat changes at any stage is critical.

\section{Equity}

Community attitudes towards equity within the project displays promising signs of social mobilisation and transformative change. All participants noted the involvement and motivation of men, women, youth and elderly in the project, acknowledging the only community members not involved were those who failed to attend from the outset.

Across both communities, female participants noted an increased ability to involve themselves in community activities and decision-making as a result of the project. The female participants reported a positive change in attitude and behaviour, noting a growth in motivation and confidence to contribute to community adaptation, as a result of their increasing involvement. At the end of this study, most female participants attended trainings and were more willing to share their knowledge and ideas. Levels of self-esteem and overall community cohesiveness were regarded as the most positive changes alongside the quality of education and awareness training:

At first I was shy and scared of talking but when CARE did more activities and training and involved us, this is where I started to build up confidence and become involved. When CARE did the water training, I was no longer scared and that is why I attended the trainings. The CDCCC trainings also taught us how to do the talking and I began to speak up for myself. (Female participant, Waisisi)

In addition to women's individual empowerment, the project has enabled the male participants to recognise the role and influence of women within the community: "their voice is much more highly considered now in decisions than before" (Male participant, Waisisi). Post-project, male participants noted an increased acknowledgment of the women's extensive contribution to the community and desire for it to continue. Prior to trainings, the majority of male participants noted that they overlooked the potential of women to contribute to decision-making and natural resource management. For example, the men started to notice:

The quantity of water used in drinking Kava (a local drink) is a lot higher than ladies are using at home for cooking. After the training we realise that Kava is using too much water so we started reducing it to give the priority to let mammas use the water. (Male participant, Waisisi) 
Regardless of the changes in attitude and behaviour, the data showed that women have a higher responsibility to continue the project. The male participants noted the women practice the management methods better than the men do. Both community focus groups concluded that women are expected to contribute more time to the project because the men have more commitments. Yet male participants note there is room for change.

\section{Impact}

The majority of participants stated that their community is better off with the CBA project implemented: "From what they have done as a result of the project, the knowledge is applied in the community" (Female participant, Imaio). At the time of this study, participants noted that they have continued to apply the knowledge gained via CARE's training to their everyday lives, appreciating the education and capacity building the project has provided towards adaptation to future changes and risks. The project has affected the overall perception of climate change, with the community widely acknowledging the need to safeguard their future via the consideration of climate change in all decisions:

Last year and the years before we can plant kumala but recently we have seen some changes - it doesn't bear much food as before. That's why in the climate change activities it clicked in our minds that it is real. (Female participant, Imaio)

The knowledge, skill set, and heightening perception of the impacts of climate change gained from the projects has "motivated us to have more ideas" (Male participant, Imaio). Both communities have been innovative in undertaking their own preventative measures and climate change adaptation activities. Within Imaio, the projects have encouraged innovation in areas such as agriculture, agroforestry and aquaculture, including the establishment of individual demonstration plots next to their homes, conservation areas in the neighbouring forests, the limitation of deforestation to prevent erosion, and the construction of a communal Tilapia fish farm.

Within Waisisi, the community has displayed innovation via the construction of storm walls to slow the impacts of sea-level rise, the planting of trees to prevent erosion, the building of cyclone resistant housing with local materials, the preservation of marine areas and the commencement of plans for relocation of the community to higher ground:

The project has influenced us to consider climate change in decision-making because climate conditions are something that all people should have a voice in because when it happens, it affects all of us from children to old people. (Male interview, Waisisi)

Both communities now hold an altered perception regarding their ability to meet climate change challenges. The project has relied on communities taking ownership of their ongoing training, education and management activities. Although the focus of this paper is on external funding from NGOs, the communities view a lack of government involvement towards increasing their ability to cope and adapt. Despite Imaio receiving visits from both the Vanuatu Fisheries Department and the Department of Rural Water Supply, both communities view CARE as the principal actor providing aid for climate change adaptation. 


\section{Sustainability}

The sustainability of the project was difficult to determine owing to the short period in which it had been implemented. At the time of this study, the communities continued to practice and implement the knowledge gained after the project ended. The potential for social sustainability of the project is present, with the training of the community and knowledge and information management being effective in supporting understandings around the impacts of climate change. Overall, comprehensive training sessions and practical demonstrations were seen to aid the ability of communities to sustain the project effectively. Participants stated that the CCA and DRR training and the water management activities have increased community motivation through the effective results observed. In comparison, the food management activities were lacking the elements of prolonged sustainability, largely due to the ineffectiveness of project outputs. Participants emphasised the activities needed to sustain motivation to ensure community ownership and responsibility of the project into the future.

Yet despite the potential for sustainability, the results indicate that the communities still depend heavily on their relationship with CARE, thereby influencing the extent to which the community can sustain the project in the long-term when funding has ceased. During transcription, CARE representatives acknowledged that the quality of what they achieved within the Tanna communities may not be as influential as in other communities where they have an ongoing presence. The sustainability of such projects relies on the community taking ownership and responsibility over the activities to ensure continued preparation, adaptation and overall success:

Once the project ends we will be responsible for sustaining the projects so it is up to us, the community, to take the lead to enable us to be better off. It is up to us whether we want it to be sustainable or not. (Female participant, Imaio)

We don't know if we would be able to do it by ourselves unless we are taught more about sustainability. (Male participant, Waisisi)

While decades of scholarship in development studies have shown the difficulties in sustaining external projects in the long term, it is imperative that external aid and funding fosters ownership from the onset. However, it is important to note that these activities and the overall project are new to these communities, and that ownership and sustainability skills hold the potential to develop over time.

\section{Discussion}

This study provides insights into key elements needed for successful resilience building in communities through CBA initiatives/projects. These elements mirror many of those that have been reported in the literature to date, but this study recognises the particular importance of local context, equity and local involvement/knowledge. Each of these will be discussed below, drawing on literature and adaptation theory, to contextualise the lessons learnt and critical focus areas for future CBA. The insights drawn from these communities in Tanna, 
Vanuatu will also demonstrate the importance of looking 'beyond SIDS' as homogenous and vulnerable.

The importance of local context and looking beyond SIDS as homogenous

After evaluating the appropriateness of the case studies, the importance of integrating context in design and implementation emerged, with participants citing that the activities and overall project effectively catered to their priorities and concerns. This is a finding that has been iterated in several other studies (e.g. Ashley et al., 2015; Remling \& Veitayaki, 2016). In sum, the contextual main risks affecting the communities were met by project aims to adapt critical livelihood assets to climate change, including food, water and overall community preparedness to respond to risks and hazards. Further, the appropriateness and relevance of the skills training and education material also meant that they could be successfully incorporated into community livelihoods. This legitimacy to the local concerns and priorities will help ensure the activity is community 'owned' and, through this, elevate the projects' ongoing sustainability (Remling \& Veitayaki, 2016).

Despite being appropriate for local context in terms of local concerns and priorities, other contextual specificities were not considered which hindered the projects' ability to reduce vulnerability and increase resilience. These include the lack of consideration for environmental context which enabled the nearby volcano to limit project effectiveness, as well as the use of non-traditional materials which produced difficulties for participants. This demonstrates how CBA projects must be tailored to not only local priorities but all specific social, political, cultural, economic and, in particular, environmental elements and vulnerabilities within a community (Ayers \& Forsyth, 2009; Schipper, 2009). This also implies that, due to these contextual differences, initiatives in one context may be unable to be replicated or will have less value in another, thus representing the challenges of scaling out a project design (Gogoi et al., 2014; Reidy, 2012; Schipper, 2009). This was previously noted by CARE, which described how the same project was successful in some islands but failed in others. Through these findings, it is evident that "the similarities of SIDS are balanced by differences" (Kelman, 2014, p. 122) and that moving beyond 'SIDS' as a group that experiences vulnerabilities in equal measures is imperative. There are, in fact, infinite diversities in vulnerability and susceptibility within the 'SIDS community' as well as between communities within SIDS, social groups and between individuals (Barnett et al., 2008; Kelman, 2014, p. 122; Moore, 2010) and these should be considered in CBA design and implementation.

Gender equality and the importance of recognising other development challenges in SIDS

CBA literature has previously acknowledged the importance of recognising the complexities within communities for supporting project effectiveness (Kirkby et al., 2017; Platteau, 2004; Richmond \& Sovacool, 2012). In evaluating the equity dimensions of this project, the ability of the implementing organisation to tackle intra-community inequalities in terms of gender emerged as a core element of success. This is a key achievement as CBA has a tendency to treat gender issues as unproblematic (Dodman \& Mitlin, 2013). CARE developed gender equality frameworks which, through focusing on building agency, changing relations and transforming structures, aims to incorporate equality and social inclusion into all phases of any project (CARE Vanuatu \& Save the Children, 2017). Through this focus on gender equality, CARE was able to foster positive shifts in women's empowerment (i.e. in terms of self-esteem 
and confidence to participate), with initial signs of transformative social change also being observed (i.e. shifts in community mindsets regarding the important role of women in adaptation and community management).

This finding also implies a connection with the previous discussion around integrating local context, as the underlying socio-political context in terms of gender relations were adequately considered in designs. Given that gender-blindness can exacerbate existing inequalities (Bryan et al., 2015; Cardona et al., 2012) and reduce the sustainability of initiatives (Denton, 2002), this aspect supports the ability of this project to tackle vulnerability rather than reinforce inequalities. This is particularly relevant for Vanuatu where previous studies specifically noted how gendered issues require amelioration if CBA initiatives are to improve wellbeing equitably (Ensor, 2016). Gender frameworks should therefore be incorporated into future CBA as when gender is addressed, adaptation "is likely to lead to greater resilience [...] ensuring the needs and priorities of both men and women are addressed" (Bryan et al., 2015).

This finding also demonstrates how a sole focus on climate change without consideration for other issues such as gender equality may counterproductively increase overall vulnerability through the reinforcement of inequalities. This is related to existing criticisms that SIDS' vulnerability to climate change has become iconised and frequently dominates policy and media discourses, thereby distracting from and depoliticising other development challenges that need to be addressed simultaneously (Gaillard, 2012; Kelman, 2014). Climate change needs to be placed within a wider political context (Kelman, 2014) and be tackled as one hazard among many root causes of vulnerability (e.g. Daly et al., 2010). This study does not argue that climate change should be denigrated as an important issue but that there is a necessity to look beyond this SIDS narrative and recognise the many other development challenges, such as gender equality, require simultaneous redress to reduce overall vulnerability (see Kelman, 2014). When this happens, climate change adaptation may then become an 'opportunity', as observed in this study, to ameliorate other underlying vulnerability sources such as gender disparity (Kelman, 2014).

\section{Local agency and looking beyond SIDS as vulnerable}

Another key finding in this study was related to the successful awareness raising, education and training which created the foundation for adaptation and resilience (Cardona et al., 2012; Gwali, 2014; Reidy, 2012). A well-informed and motivated population, aware of the need to adapt, increases participation and success of project implementation (Ayers \& Forsyth, 2009; Cardona et al., 2012). Related to receiving a range of important trainings to enrich adaptive capacities, participants also exhibited independent, innovative natures whereby both communities undertook their own preventative measures and adaptation activities within and outside of CARE's implemented projects. This was a core element of success related to the impact criterion in this study. Fostering innovation is essential for the ability of CBA to reduce vulnerability and increase resilience in the long-term as it supports the sustainability of initiatives (Bene et al., 2014; Simane \& Zaitchik, 2014). This highlights the importance of fostering spaces in which locals can experiment, learn, reflect on and communicate ideas (Reed et al., 2013). Furthermore, innovation may be important in the development of adaptation that simultaneously reduces poverty and vulnerability to climate change, thereby having connotations to previous discussions (Reed et al., 2013). 
This finding, in accordance with other studies (Campbell, 2009), also demonstrates the necessity of looking beyond SIDS communities as inherently vulnerable. More specifically, the character of SIDS should not be based on assumptions or stereotypes related to inherent vulnerability, but recognise the resilience and capacity that already exists, and has existed, through times of stress and uncertainty (Kelman, 2018). This study supports the notion that a system is both resilient and vulnerable, and that climate change adaptation must enable local agents to foster change in their own lives (Campell, 2009; Dixon \& Stringer, 2015; Kelman \& West, 2009; Reid \& Schipper, 2014). This is where the criticality of local involvement and participation is also relevant as this allows for the effective integration of traditional knowledge related to these innovations as well as the concomitant heightening of ownership and local support for initiatives (Maclellan, 2015; Richmond \& Sovacool, 2012; UNFCCC, 2007).

\section{Concluding recommendations}

In light of the lack of global progress towards curbing greenhouse gas emissions and the maladaptive outcomes of top-down adaptation approaches, this study concludes that CBA has both elements of success and failure that influence communities' ability to reduce vulnerability and increase resilience. Both positive and negative aspects of the evaluated CBA project contribute towards key recommendations that should be considered for optimising future $\mathrm{CBA}$ as a promising alternative to top-down approaches. The findings also illuminate the importance of looking beyond existing assumptive narratives related to SIDS.

Three core recommendations have been generated for effective future CBA. The first is the upmost importance of integrating economic, political, environmental and social contextual specificities in CBA design and implementation. This implies the need for critical analysis of community contexts to recognise elements that have the potential to limit success and sustainability. The second recommendation is related to the integration of gender equality frameworks in CBA design, implementation and evaluation as this will ensure the success of initiatives while limiting the potential for maladaptation and exacerbation of vulnerabilities. More specifically, a focus on women's roles and voices in society, and continued gender training within projects and existing committees, is crucial to begin to transform culturally constructed inequality. In addition, pursuing the collection of gender-disaggregated data to address and monitor entrenched inequalities throughout implementation and evaluation is also imperative. The third recommendation is related to recognising the resilience of, and more specifically the innovative nature of, local communities and to integrate as well as complement these in CBA initiatives. In exploring these successful elements of effective adaptation, this study also demonstrated the need to look beyond SIDS as homogenous, primarily only vulnerable to climate change and as lacking resilience.

\section{Acknowledgements}

Many thanks to the communities of Imaio and Waisisi, Vanuatu, for their warm hospitality and invaluable participation. This research would not have been possible without the support and assistance of CARE in Vanuatu: special thanks to Candice Holt, Sandra Silas and Fenda Sam. This project was funded through ARC Linkage project (LP160100941). 


\section{References}

Adger, W. (2006). Vulnerability. Global Environmental Change, 16(3), 268-281. https://doi.org/10.1016/j.gloenvcha.2006.02.006

Ashley, L., Zhumanova, M., Isaeva, A., \& Dear, C. (2015). Examining changes in local adaptive capacity resulting from climate change adaptation programming in rural Kyrgyzstan. Climate and Development, 8(3), 281-287. https://doi.org/10.1080/17565529.2015.1034230

Ayers, J., \& Forsyth, T. (2009). Community-based adaptation to climate change. Environment: Science and Policy for Sustainable Development, 51(4), 22-31. https://doi.org/10.3200/ENV.51.4.22-31

Bahadur, A., Ibrahim, M., \& Tanner, T. (2010). The resilience renaissance? unpacking of resilience for tackling climate change and disasters. Retrieved from Institute of Development Studies https://opendocs.ids.ac.uk/opendocs/bitstream/handle/123456789/2368/The\%20resi lience $\% 20$ renaissance.pdf?sequence $=1 \&$ is Allowed $=\mathrm{y}$

Barnett, J., Lambert, S., \& Fry, I. (2008). The hazards of indicators: insights from the environmental vulnerability index. Annals of the Association of American Geographers, 98(1), 102-119. https://doi.org/10.1080/00045600701734315

Barnett, J., \& Waters, E. (2016). Rethinking the vulnerability of small island states: climate change and development in the Pacific Islands. In J. Grugel \& D. Hammett (Eds.) The Palgrave Handbook of International Development (pp. 731-748). London, UK: Palgrave Macmillan. https://doi.org/10.1057/978-1-137-42724-3 40

Bendlin, L. (2014). Women's human rights in a changing climate: highlighting the distributive effects of climate policies. Cambridge Review of International Affairs, 27(4), 680-698. https://doi.org/10.1080/09557571.2014.960507

Bene, C., Newsham, A., Davies, M., Ulrichs, M., \& Godfrey-Wood, R. (2014). Review article: resilience, poverty and development. Journal of International Development, 26(5), 598-623. https://doi.org/10.1002/jid.2992

Betzold, C. (2015). Adapting to climate change in small island developing states. Climatic Change, 133(3), 481-489. https://doi.org/10.1007/s10584-015-1408-0

BOM \& CSIRO (2014). Climate variability, extremes and change in the western tropical pacific: new science and updated country reports. Pacific Climate Change Science. https://www.pacificclimatechangescience.org/wpcontent/uploads/2014/07/PACCSAP CountryReports2014 WEB 140710.pdf

Bours, D., McGinn, C., \& Pringle, P. (2013). Monitoring and evaluation for climate change adaptation: a synthesis of tools, frameworks and approaches. UKCIP. https://ukcip.ouce.ox.ac.uk/wp-content/PDFs/SEA-change-UKCIP-MandEreview.pdf

Bryan, E., \& Behrman, J. (2013). Community-based adaptation to climate change: A theoretical framework, overview of key issues and discussion of gender differentiated priorities and participation (CAPRi Working Paper No. 109). International Food Policy Research Institute. http://ebrary.ifpri.org/cdm/ref/collection/p15738coll2/id/127540

Bryan, E., Kristjanson, P., \& Ringler, C. (2015). Why paying attention to gender matters for Climate Change adaptation. International Food Policy Research Institute, 12 November. http://www.ifpri.org/blog/why-paying-attention-gender-matters-climate-change-adaptation 
Buggy, L., \& McNamara, K.E. (2016). The need to reinterpret 'community' for climate change adaptation: a case study of Pele Island, Vanuatu. Climate and Development, 8(3), 270-280. https://doi.org/10.1080/17565529.2015.1041445

Campbell, J. (2009). Islandness: vulnerability and resilience in Oceania. Shima, 3(1), 85-97.

Cardona, O.D., Van Aalst, M.K., Birkmann, J., Fordham, M., McGregor, R., Perez, R., Pulwarty, R.S., Schipper, L., \& Sinh, B. (2012). Determinants of risk: exposure and vulnerability. In C.B. Field, V. Barros, T.F. Stocker, D. Qin, D.J. Dokken, K.L. Ebi, M.D. Mastrandrea, K.J. Mach, G.K. Plattner,S.K Allen, M. Tignor \& P.M. Midgley (Eds.) Managing the Risks of Extreme Events and Disasters to Advance CC Adaptation: A Special Report of Working Groups I and II of the IPCC (pp. 65-108). Cambridge, UK \& New York, USA: Cambridge University Press. https://doi.org/10.1017/CBO9781139177245.005

CARE Vanuatu \& Save the Children (2017). Yumi Redi Long Klaemet Jenis: increasing small island resilience to Climate Change in Vanuatu. Port Vila, Vanuatu: CARE International.

Daly, M., Namouta, P., Nelson, F., \& Kohlhase, J. (2010). Reducing the climate vulnerability of coastal communities in Samoa. Journal of International Development, 22(2), 265-281. https://doi.org/10.1002/jid.1678

Demetriades, J. (2007). Gender Indicators: What, Why and How?. OECD. http://www.oecd.org/dac/gender-development/43041409.pdf

Denton, F. (2002). Climate Change vulnerability, impacts, and adaptation: why does gender matter?. Gender and Development, 10(2), 10-20. https://doi.org/10.1080/13552070215903

Dinnen, S., Jowitt, A., \& Newton, T. (2010). Kind of mending: restorative justice in the Pacific Islands. Canberra, ACT: ANU Press.

Dixon, J., \& Stringer, C. (2015). Towards a theoretical grounding of climate resilience assessments for smallholder farming systems in Sub-Saharan Africa. Resources, 4(1), 128154. https://doi.org/10.3390/resources 4010128

Dodman, D., \& Mitlin, D. (2013). Challenges for community-based adaptation: discovering the potential for transformation. Journal of International Development, 25(5), 640-659. https://doi.org/10.1002/jid.1772

Ensor, J. (2016). Resilience Realities: Resilience and Development Practice in Vanuatu. White Rose Research.

Ensor, J.E., Park, S.E.., Attwood, S.J., Kaminski, A.M., \& Johnson, J.E. (2018). Can community-based adaptation increase resilience?. Climate and Development, 10(2), 134151. https://doi.org/10.1080/17565529.2016.1223595

Folke, C. (2006). Resilience: the emergence of a perspective for social-ecological systems analyses. Global Environmental Change, 16(3), 253-267. https://doi.org/10.1016/j.gloenvcha.2006.04.002

Folke, C., Carpenter, S.R., Walker, B., Scheffer, M., Chapin, T., \& Rockstrom, J. (2010). Resilience thinking: integrating resilience, adaptability and transformability. Ecology and Society, 15(4), 1-9. https://doi.org/10.5751/ES-03610-150420

Gaillard, J.C. (2012). The climate gap. Climate and Development, 4(4), 261-264. https://doi.org/10.1080/17565529.2012.742846

Gogoi, E., Dupar, M., Jones, L., Martinez, C., \& McNamara, L. (2014). Enablers for delivering community-based adaptation at scale. Climate and Development, 6(4), 368371. https://doi.org/10.1080/17565529.2014.918869 
Gwali, S. (2014). Building community based adaptation and resilience to climate change in Uganda. Paper presented to the Farmer Managed Natural Regeneration National Conference. Kampala, Uganda: World Vision, July.

Hedger, M., Mitchell, T., Leavy, J., Greely, M., \& Downie, A. (2008). Evaluation of adaptation to climate change from a development perspective. PreventionWeb. https://www.preventionweb.net/files/7845 GEF20final20report20Oct20081.pdf

Heintz, H., Kirch, L., Kuppers, B., Mann, H., Mischo, F., Mucke, P., Pazdzierny, T., Prutz, R., Radtke, K., Strube, F., \& Weller, D. (2018). World Risk Report 2018. ReliefWeb. https://reliefweb.int/sites/reliefweb.int/files/resources/WorldRiskReport-2018.pdf

Interagency Resilience Working Group (2012). The characteristics of resilience building: a discussion paper. Technical Consortium for Building Resilience in the Horn of Africa. http://technicalconsortium.org/wp-content/uploads/2014/05/The-Characteristicsof-Res Building.pdf

IPCC (2013). Climate Change 2013: The Physical Science Basis. Contribution of Working Group I to the Fifth Assessment Report of the Intergovernmental Panel on Climate Change. IPCC. https://www.ipcc.ch/site/assets/uploads/2018/02/WG1AR5 all final.pdf

Kais, S., \& Islam, S. (2016). Community capitals as community resilience to Climate Change: conceptual connections. International Journal of Environmental Research and Public Health, 13(12), 1211. https://doi.org/10.3390/ijerph13121211

Kelman, I. (2018). Islandness within climate change narratives of small island developing states (SIDS). Island Studies Journal, 13(1), 149-166. https://doi.org/10.24043/isj.52

Kelman, I. (2014). No change from climate change: vulnerability and small island developing states. The Geographical Journal, 180(2), 120-129. https://doi.org/10.1111/geoj.12019

Kelman, I., \& West, J. (2009). Climate change and small-island developing states: a critical review. Ecological and Environmental Anthropology, 5(1), 1-16.

Kirkby, P., Williams, C., \& Huq, S. (2017). Community-based adaptation (CBA): adding conceptual clarity to the approach, and establishing its principles and challenges. Climate and Development, 10(7), 577-589. https://doi.org/10.1080/17565529.2017.1372265

Maclellan, N. (2015). Yumi stap redi long klaemet jenis: Lessons from the Vanuatu NGO Climate Change Adaptation Program. Oxfam. https://www.oxfam.org.au/wpcontent/uploads/2015/05/lessons-from-the-vanuatu-ngo-climate-change-adaptationprogram-web.pdf

Malatesta, S., \& Schmidt di Friedberg, M. (2017). Environmental policy and climate change vulnerability in the Maldives: from the 'lexicon of risk' to social response to change. Island Studies Journal, 12(1), 53-70. https://doi.org/10.24043/isj.5

McNamara, K.E. (2013). Taking stock of community-based climate-change adaptation projects in the Pacific. Asia Pacific Viewpoint, 54(3), 398-405. https://doi.org/10.1111/apv.12033

Métrich, N., Allard, P., Aiuppa, A., Bani, P., Bertagnini, A., Shinohara, H., Parello, F., Di Muro, A., Garaebiti, E., Belhadj, O., \& Massare, D. (2011). Magma and Volatile Supply to Post-collapse Volcanism and block resurgence in Siwi Caldera (Tanna Island, Vanuatu Arc). Journal of Petrology, 52(6), 1077-1105. https://doi.org/10.1093/petrology/egr019 
Moore, A. (2010). Climate changing small islands: considering social science and the production of island vulnerability and opportunity. Environment and Society: Advances in Research, 1, 116-131. https://doi.org/10.3167/ares.2010.010106

NACCC (2007). National Adaptation Programme for Action (NAPA). PreventionWeb. https://www.preventionweb.net/files/8580 vut01.pdf

Nunn, P.D., Aalbersberg, W., Lata, S., \& Gwilliam, M. (2014). Beyond the core: community governance for climate-change adaptation in peripheral parts of Pacific Island Countries. Regional Environmental Change, 14(1), 221-235. https://doi.org/10.1007/s10113-013-0486-7

Nunn, P.D., \& Kumar, R. (2018). Understanding climate-human interactions in Small Island Developing States (SIDS): implications for future livelihood sustainability. International Journal of Climate Change Strategies and Management, 10(2), 245-271. https://doi.org/10.1108/IJCCSM-01-2017-0012

Nurse, L., McLean, R., Agard, J., Briguglio, L.P., Duvat, V., Pelesikoti, N., Tompkins, E., \& Webb, A. (2014). Small islands. In V.R. Barros, C.B. Field, D.J. Dokken, M.D. Mastrandrea, K.J. Mach, T.E. Bilir, M. Chatterjee, K.L. Ebi, Y.O. Estrada, R.C. Genova, B. Girma, E.S. Kissel, A.N. Levy, S. MacCracken, P.R. Mastrandrea \& L.L. White. (Eds.) Climate Change 2014: Impacts, Adaptation, and Vulnerability. Part B: Regional Aspects. Contribution of Working Group II to the Fifth Assessment Report of the Intergovernmental Panel on Climate Change (pp. 1613-1654). Cambridge \& New York: Cambridge University Press.

Platteau, J. (2004). Monitoring elite capture in community-driven development. Development and Change, 35(2), 223-246. https://doi.org/10.1111/j.1467-7660.2004.00350.x

Reed, M.S., Podesta, G., Fazey, I., Geeson, N., Hessel, R., Hubcek, K., Letson, D., Nainggolan, D., Prell, C., Rickenbach, M.G., Ritsema, C., Schwilch, G., Stringer, L.C., \& Thomas, A.D. (2013). Combining analytical frameworks to assess livelihood vulnerability to climate change and analyse adaptation options. Ecological Economics, 94, 66-77. https://doi.org/10.1016/j.ecolecon.2013.07.007

Reid, H. (2015). Ecosystem- and community-based adaptation: learning from communitybased natural resource management. Climate and Development, 8(1), 4-9. https://doi.org/10.1080/17565529.2015.1034233

Reid, H., Alam, M., Berger, P., Cannon, T., Huq, S., \& Milligan, A. (2009). Community based adaptation to climate change: an overview. Participatory Learning and Action, 60, 11-33.

Reid, H., Begum, M., Colenbrander, S., Jackson, A., Richter, L-K.M.A., Walji, A., \& Winters, M. (2016). Community based adaptation: enhancing urban community resilience. Paper presented to the 10th International Conference on Community Based Adaptation. Dhaka, Bangladesh: International Institute for Environment and Development, April.

Reid, H., \& Schipper, L. (2014). Upscaling community based adaptation: An introduction to the edited volume. In J.S. Ayers, L. Reid, H. Huq, S. \& Rahman, A. (Eds.) Community based Adaptation to Climate Change: Scaling it up (pp. 3-21). New York: Routledge.

Reidy, C. (2012). Engaging Communities in Climate Change Adaptation: a case study from North East Victoria. Paper presented to Coastal Conference. Sydney, NSW: East Coast Conferences. 
Remling, E., \& Veitayaki, J. (2016). Community-based action in Fiji’s Gau Island: a model for the Pacific?. International Journal of Climate Change Strategies and Management, 8(3), 375-398. https://doi.org/10.1108/IJCCSM-07-2015-0101

Richmond, N., \& Sovacool, B. (2012). Bolstering resilience in the coconut kingdom: improving adaptive capacity to climate change in Vanuatu. Energy Policy, 50, 843-848. https://doi.org/10.1016/j.enpol.2012.08.018

Schipper, L. (2009). Expanding the community of community-based adaptation. Stockholm Environment Institute.

https://mediamanager.sei.org/documents/Publications/Sustainablelivelihoods/Vulnerability approach to livelihood development/ExpandingCommunity-Community-Based-Adaptation.pdf

Schmaljohann, M., \& Prizzon, A. (2014). The age of choice: Fiji and Vanuatu in the new aid landscape. Overseas Development Institute. https://www.odi.org/sites/odi.org.uk/files/odi-assets/publications-opinion-files/9147.pdf

Simane, B., \& Zaitchik, B. (2014). The sustainability of community based adaptation projects in the Blue Nile Highlands of Ethiopia. Sustainability Science, 6, 4309-4325.

Smit, B., \& Wandel, J. (2006). Adaptation, adaptive capacity and vulnerability. Global Environmental Change, 16(3), 282-292. https://doi.org/10.1016/j.gloenvcha.2006.03.008

UNDP (2010). Gender, climate change and community based adaptation: A guidebook for designing and implementing gender-sensitive community-based adaptation programmes and projects. UNDP. New York: United Nations Development Program.

UNFCCC (2007). Climate Change: impacts, vulnerabilities and adaptation in developing countries. UNFCCC. https://unfccc.int/resource/docs/publications/impacts.pdf

United Nations (2015). The permanent mission of the Republic of Vanuatu to the United Nations. United Nations. https://www.un.int/vanuatu/vanuatu/climate-change

Villanueva, P.S. (2011). Learning to ADAPT: monitoring and evaluation approaches in climate change adaptation and disaster risk reduction - challenges, gaps and ways forward (SCR Discussion Paper 9). Institute of Development Studies. https://www.ids.ac.uk/files/dmfile/SilvaVillanueva 2012 Learning-toADAPTDP92.pdf

Webb, J., Damon, C., Savua, I., Marango, J., Maliliu, E., Toto, M., Charley, J.B., Silas, M., \& Silas, S. (2017). Does gender responsive disaster risk reduction make a difference?. CARE International.

https://www.care.org.au/wpcontent/uploads/2017/09/CARE Vanuatu DRR Impact Study 3 FINAL web a mend.pdf

Wheeler, T., \& Von Braun, J. (2013). Climate Change impacts on global food security. Science, 341(6145), 508-513. https://doi.org/10.1126/science.1239402 